NASA/TM-2002-211203

AIAA-2001-5018

\title{
Behavior of Rapidly Sheared Bubble Suspensions
}

\author{
A.S. Sangani and V.I. Kushch \\ Syracuse University, Syracuse, New York \\ M. Hoffmann and H. Nahra \\ Glenn Research Center, Cleveland, Ohio \\ D.L. Koch and Y. Tsang \\ Cornell University, Ithaca, New York
}


Since its founding, NASA has been dedicated to the advancement of aeronautics and space science. The NASA Scientific and Technical Information (STI) Program Office plays a key part in helping NASA maintain this important role.

The NASA STI Program Office is operated by Langley Research Center, the Lead Center for NASA's scientific and technical information. The NASA STI Program Office provides access to the NASA STI Database, the largest collection of aeronautical and space science STI in the world. The Program Office is also NASA's institutional mechanism for disseminating the results of its research and development activities. These results are published by NASA in the NASA STI Report Series, which includes the following report types:

- TECHNICAL PUBLICATION. Reports of completed research or a major significant phase of research that present the results of NASA programs and include extensive data or theoretical analysis. Includes compilations of significant scientific and technical data and information deemed to be of continuing reference value. NASA's counterpart of peerreviewed formal professional papers but has less stringent limitations on manuscript length and extent of graphic presentations.

- TECHNICAL MEMORANDUM. Scientific and technical findings that are preliminary or of specialized interest, e.g., quick release reports, working papers, and bibliographies that contain minimal annotation. Does not contain extensive analysis.

- CONTRACTOR REPORT. Scientific and technical findings by NASA-sponsored contractors and grantees.
- CONFERENCE PUBLICATION. Collected papers from scientific and technical conferences, symposia, seminars, or other meetings sponsored or cosponsored by NASA.

- SPECIAL PUBLICATION. Scientific, technical, or historical information from NASA programs, projects, and missions, often concerned with subjects having substantial public interest.

- TECHNICAL TRANSLATION. Englishlanguage translations of foreign scientific and technical material pertinent to NASA's mission.

Specialized services that complement the STI Program Office's diverse offerings include creating custom thesauri, building customized data bases, organizing and publishing research results ... even providing videos.

For more information about the NASA STI Program Office, see the following:

- Access the NASA STI Program Home Page at http://www.sti.nasa.gov

- E-mail your question via the Internet to help@sti.nasa.gov

- Fax your question to the NASA Access Help Desk at 301-621-0134

- Telephone the NASA Access Help Desk at 301-621-0390

- Write to:

NASA Access Help Desk

NASA Center for AeroSpace Information 7121 Standard Drive

Hanover, MD 21076 
NASA/TM-2002-211203

\section{Behavior of Rapidly Sheared Bubble Suspensions}

A.S. Sangani and V.I. Kushch

Syracuse University, Syracuse, New York

M. Hoffmann and H. Nahra

Glenn Research Center, Cleveland, Ohio

D.L. Koch and Y. Tsang

Cornell University, Ithaca, New York

Prepared for the

International Space Station Utilization-2001

sponsored by the American Institute of Aeronautics and Astronautics

Cape Canaveral, Florida, October 15-18, 2001

National Aeronautics and

Space Administration

Glenn Research Center 


\section{Acknowledgments}

This work is supported by NASA under grant number NAG3-1853.

Trade names or manufacturers' names are used in this report for identification only. This usage does not constitute an official endorsement, either expressed or implied, by the National Aeronautics and Space Administration.

Available from

NASA Center for Aerospace Information 7121 Standard Drive

Hanover, MD 21076
National Technical Information Service 5285 Port Royal Road Springfield, VA 22100 


\title{
BEHAVIOR OF RAPIDLY SHEARED BUBBLE SUSPENSIONS
}

\author{
A.S. Sangani and V.I. Kushch \\ Department of Chemical Engineering and Materials Science \\ Syracuse University \\ Syracuse, New York 13244 \\ M. Hoffmann and $H$. Nahra \\ National Aeronautics and Space Administration \\ Glenn Research Center \\ Cleveland, Ohio 441.35 \\ D.L. Koch and Y. Tsang \\ Department of Chemical Engineering \\ Cornell University \\ Ithaca. New York
}

\begin{abstract}
An experiment to be carried out aboard the International Space Station is described. A suspension consisting of millimeter-sized bubbles in water containing some dissolved salt, which prevents bubbles from coalescing. will be sheared in a Couette cylindrical cell. Rotation of the outer cylinder will produce centrifugal force which will tend to accumulate the bubbles near the inner wall. The shearing will enhance collisions among bubbles creating thereby bubble phase pressure that will resist the tendency of the bubbles to accumulate near the inner wall. The bubble volume fraction and velocity profiles will be measured and compared with the theoretical predictions. Ground-based research on measurement of bubble phase properties and flow in vertical channel are described.
\end{abstract}

\section{INTRODUCTION}

Hydrodynamic interactions and direct particle collisions can have a dramatic influence on the flow properties of suspensions in which the disperse phase volume fraction is 0.1 or greater. Over the last thirty years analytical theories, numerical simulations, and careful experiments using well defined suspensions in simple flows have provided considerable progress toward a quantitative description of the rheology of concentrated, low Reynolds number (based on particle size and characteristic velocity) suspensions (i.e., Nott and Brady 1994). The effects of dispersed particles, drops, or bubbles with the high Reynolds number flow of a suspension is likely to be even more dramatic because of the enhanced transport of momentum due to Reynolds stresses. However, most previous theories of high Reynolds number suspensions have considered only interactions of particles with the mean flow while neglecting particle-particle interactions.

The treatment of particle interactions in inertial suspensions is more difficult than in viscous suspensions for several reasons. The equations of motion for a low Reynolds number fluid are quasisteady and linear. indicating that the flow responds instantaneously to changes in the particle configuration. This feature is essential to the methods of theoretical analysis and numerical simulations used to treat most low Reynolds number suspensions. A general, moderate or high Reynolds number flow is neither quasisteady nor linear with the result that the fluid flow at any instant in time in inertial suspensions depends on the time history of the particle positions and velocities and one cannot use the analytical and numerical techniques developed for small Reynolds number, linearized equations of motion. As a result, little is known about the equations of motion for inertial suspensions of particles or drops.

However, there is a special case of an inertial suspension that is particularly amenable to theoretical analysis: a suspension of surfactant-free, spherical, high Reynolds number bubbles. In this case, the vorticity produced by the bubble motion is small and the flow induced by the bubbles may be described using the potential flow approximation. ${ }^{6}$ The fluid velocity may then be expressed as the gradient of potential obtained by solving Laplace's equation. It is possible then to derive from first principles the equations of motion for this type of bubble 
suspension. ${ }^{2,4,10,13,16}$ In addition, numerical simulation of motion of many interacting bubbles can be conducted to aid in developing the equations of motion for such bubble suspensions. The potential flow approximation is applicable in the limits of high bubble Reynolds number and small Weber number $W e=\rho V_{c}^{2} a / \sigma, \rho$ being the liquid density, $V_{c}$ the bubble characteristic velocity, $a$ the bubble radius, and $\sigma$ the interfacial tension. It also requires that there be negligible Marangoni effects, so that the tangential stress at the gas-liquid interface is negligible. Comparison between measured rise velocities of gas bubbles in water and theoretical predictions indicate that the potential flow theory for spherical bubbles is reasonably accurate for bubbles of about 1 -mm-diameter and the agreement between the theory and experiments can be improved further by including the effects of bubble deformation. ${ }^{3.7}$

In addition to the theoretical simplification of the equations of motion at low Reynolds numbers, studies of viscous suspensions have been benefitted from the ability of experimental researchers to isolate and study separately the effects of buoyancy and shearing motion on the suspension structure and rheology. Simple shear flow of a viscous suspension can be obtained by matching the density of the fluid and the particles and/or using a very viscous fluid so that the particles do not settle appreciably during the time of the experiment. While density matching is possible, ${ }^{1}$ it cannot be used for bubble suspensions which are most amenable to theoretical treatment.

Equations of motion for bubble suspensions with particular attention to the effects of shearing motion have been developed. ${ }^{4}$ For simplicity, bubble-bubble coalescence was neglected. Coalescence can be greatly reduced or avoided without introducing Marangoni effects by using an aqueous electrolyte solution as the continuous phase. Shearing a bubble suspension drives bubble-bubble collisions and the work done to shear the suspension provides a source of kinetic energy for the randomly fluctuating motions of the bubbles. This kinetic energy is dissipated by viscous drag and the balance of shear work and viscous dissipation creates a steady state bubblephase kinetic energy. The bubbles' random motion and bubble-bubble collisions drive bubbles from regions of high volume fraction to regions of low volume fraction: this phenomenon is described in terms of a bubble-phase pressure. In addition, the bubbles give rise to an effective viscosity that increases the tangential stress required to shear the bubbly liquid. A critical test of these novel, theoretical predictions requires a microgravity experiment in which the effects of shearing can be isolated and measured without the confounding influence of buoyancy driven motion.
In addition to their role as a model suspension for which the inertial effects can be studied analytically, the bubble suspensions are also of considerable practical importance as they are encountered in nuclear reactors, fermenters used in biotechnology, and bubble column reactors. Equations of motion of bubbly liquids validated with simple, well defined experiments will be useful in designing the equipment used in these processes. It is also expected that the experience gained with the microgravity experiment will help predict the behavior of bubble suspensions to be encountered in space processing.

Section 2 describes briefly the experiment to be carried out aboard the International Space Station. Section 3 describes the ground-based and low gravity-based research aimed at developing techniques for creating nearly uniform sized, noncoalescing bubble suspensions and measuring bubble volume fraction and velocity distribution. These techniques are being used to study buoyancy driven flow in vertical and inclined channels. Section 4 outlines theoretical framework that will be tested through the experiments.

\section{THEMICROGRAVITY EXPERIMENT}

Figure 1 shows the schematics of the experiments to be carried out on the International Space Station. A suspension of gas bubbles of approximately 2 -mm-diameter in an aqueous solution will be created inside a cylindrical Couette cell. The centrifugal force produced by rotating the outer cylinder will drive the bubbles toward the inner cylinder of the Couette device. However, the shear flow in the gap will create randomly fluctuating bubble velocities and an associated bubble phase pressure. This pressure will resist the accumulation of bubbles and lead to steady state profile of bubble phase volume fraction as a function of

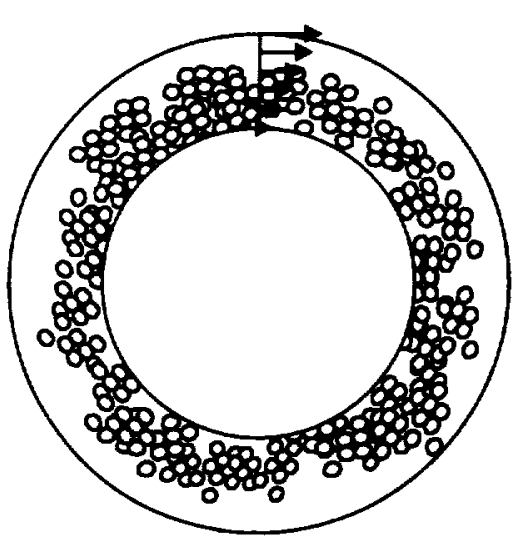

Figure 1.-Schematic of the experiment to be carried in the Couette cell. 
radial position. Hot-film anemometers and dual impedance probes to be described in the next section will be traversed across the gap to determine the bubble volume fraction, velocity, and velocity variance. In addition, a hot film probe mounted flush with the wall will be used to determine the wall shear stress. A comparison of experimentally measured volume fraction, velocity, and velocity variance profiles and wall shear stress with theoretical predictions will provide a critical test of the averaged equations of motion for bubble suspensions and in particular will demonstrate the importance of the bubble phase pressure and viscosity.

Although there is no Taylor-Couette instability when the outer cylinder is rotated, there is still a transition to turbulent flow at significantly high shear rates. ${ }^{14}$ This transition will occur in pure water in our Couette design at a shear rate of $27 \mathrm{~s}^{-1}$. We will conduct some of our experiments well below this critical shear rate so that we can be assured of laminar flow. However, an interesting question that the experiment will help us address is whether the effective viscosity produced by the random shear induced bubble velocities will stabilize the flow. Photography of the Couette cell and examination of the spatial and temporal correlations of the probe signals will be used to test for flow instabilities.

\section{GROUND-BASED AND LOW GRAVITY-BASED EXPERIMENTS}

\section{Ground-Based Experiments}

The ground-based experimental research is focused on (i) producing nearly monodisperse, noncoalescing bubble suspensions; (ii) developing probes for measuring volume fraction and velocity profiles of bubbles; (iii) understanding bubble-wall interactions; and (iv) measurements for flow induced by buoyancy in vertical and inclined channels.

The experimental setup for measurements in vertical channel is shown in Figure 2. The plexiglass cell has a 2by $20-\mathrm{cm}$ cross-section and the height of $200 \mathrm{~cm}$. Nitrogen gas is introduced at the base of the channel through an array about $100-\mu \mathrm{m}$-diameter and 65 -mm-long capillaries arranged in a hexagonal array with about 28 capillaries per square $\mathrm{cm}$. The flow rate per capillary used in the experiments is small enough so that the bubble size could be expected to be independent of flow rate. ${ }^{9.17}$ A 0.05

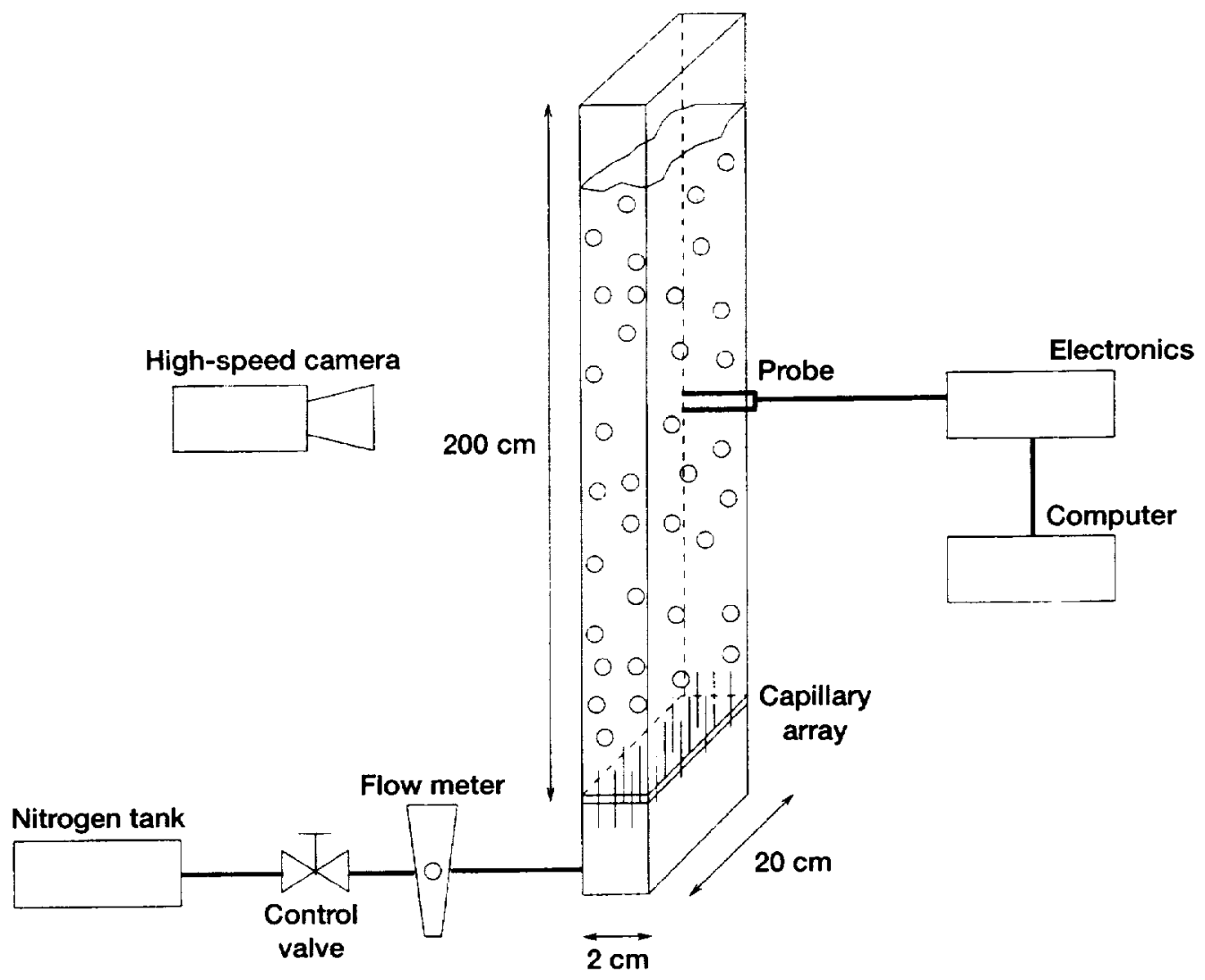

Figure 2.-Experimental setup of ground-based vertical channel experiments. 

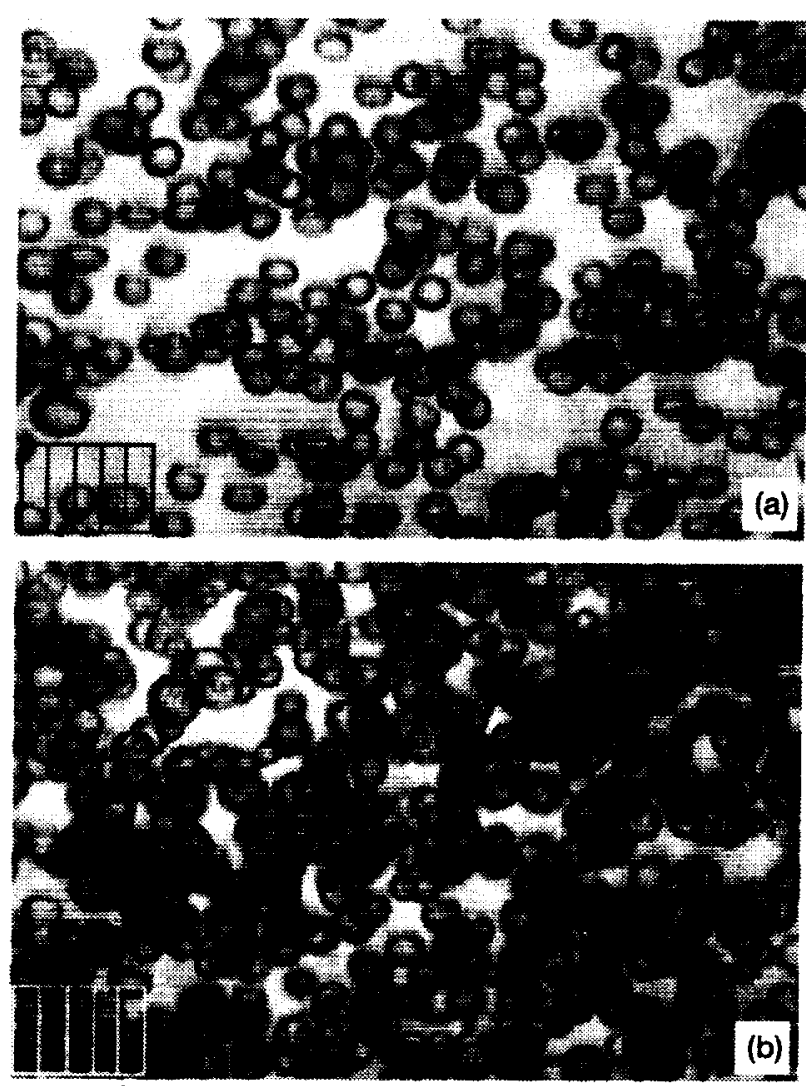

Figure 3.-Bubble size and distribution for typical mean gas volume fractions $\alpha$. The spacing in the grid is $1 \mathrm{~mm}$. (a) $\alpha=0.05$. (b) $\alpha=0.10$.

molar solution of $\mathrm{MgSO}_{4}$ in water was used to inhibit coalescence.

Figure 3 shows photographs of the bubble suspension at volume fractions of 0.05 and 0.10 . The bubbles are seen to be nearly monodisperse with an average diameter of about $1.5 \mathrm{~mm}$. Also seen is evidence of clustering of the bubbles in the plane normal to gravity, although the extent of clustering is not as great as seen in the numerical simulations based on potential flow. ${ }^{11,12,15}$

Figures 4 and 5 show, respectively, the hot-wire and dual impedance probes used for the measurements. The voltage signals from the dual impedance probes can be autocorrelated to determine the velocity distribution of the bubbles near the probe. The data obtained from the hotwire can be used to determine the liquid velocity variance and the frequency of collisions between the bubbles and the probe. The latter can be related to the bubble volume fraction and velocity variance.

Representative measurements made with these probes and the setup for vertical channel are shown in Figures 6 to 8 . Figure 6 shows the aspect ratio of the bubbles as a function of bubble volume fraction. At larger volume fractions the rise velocity of the bubbles decreases and this causes a decrease in the Weber number, the ratio of inertial to surface tension forces, resulting in bubbles that are less deformed at higher volume fractions. The solid line in the figure corresponds to Moore's prediction ${ }^{7}$ based on an analysis of a single bubble. The bubble phase velocity variance as a function of volume fraction is shown in Figure 7. We see a nearly linear dependence. The results for larger volume fractions extrapolated to zero volume fraction, however, do not give zero variance at zero volume fraction. The wall effects are responsible for this anomalous behavior. ${ }^{17}$ Figure 8 shows average rise velocity as a function of bubble volume fraction. Once again the behavior for very dilute bubble suspensions is seen to be different from that obtained by extrapolating higher volume fraction results to small volume fractions.

\section{Low Gravity-Based Experiments}

Low gravity-based experiments performed on the KC135 low gravity facility are focused on the implementation of the diagnostics used for measurement of the local bubble volume fraction and velocity profiles. These experiments are also aimed at the verification of performance of a bread-board Couette system which includes the Couette cell, a two-phase separator, probe diagnostics, and bubble generation subsystem.

The Couette assembly includes a $30-\mathrm{cm}$-high Couette consisting of a 24-cm-diameter 303 SS stationary inner wall, and 30-cm-diameter acrylic outer wall. The Couette holds approximately 7.6 liters of water between the inner and outer cylinders. Magnesium sulfate $\left(\mathrm{MgSO}_{4}\right)$ salt will be added to the water in the Couette to create a 0.05 molar solution to inhibit bubble coalescence. The outer wall is optically clear and is constructed from one piece of acrylic. The outer cylinder rotates from 0 to $100 \mathrm{rpm}$ using a $1 / 2$ HP motor with speed controller. The inner wall consists of 4 segments of the inner cylinder mounted together using 4 splice plates. A (3- by $3-\mathrm{cm}$ ) acrylic window is mounted to one of the 4 inner wall segments for imaging the bubbles near the inner wall. The acrylic top and stainless steel bottom of the Couette rotate with the outer cylinder. The bottom includes acrylic windows to provide a light source for illuminating the Couette. The Couette bottom seal material is polymer filled Teflon ${ }^{\circledR}$. The top uses the same, but a smaller seal design. Two seals provide double containment at all sealing surfaces on the Couette except for the splice plates on the inner cylinder that are equipped with a single gasket seal. The Couette assembly is designed and verified to withstand $7.5 \mathrm{psig}$. Figure 9 shows a picture of the Couette integrated into the KC-135 rig. 


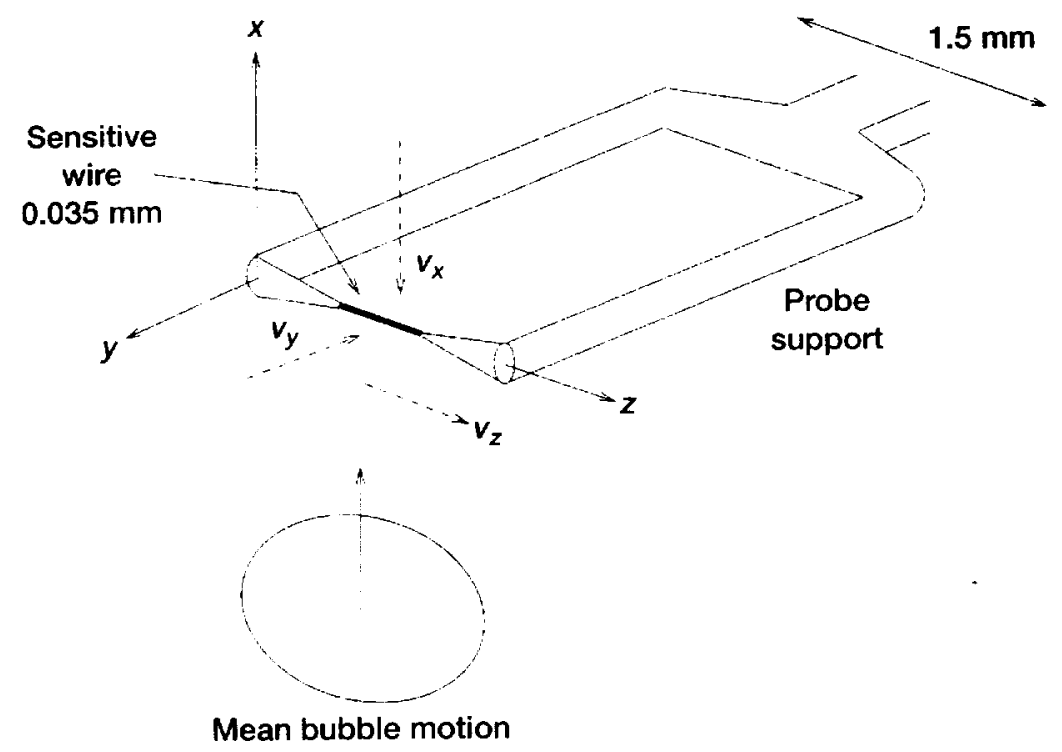

Figure 4.-Schematic of the hot-wire probe and its orientation with respect to the mean bubble motion.

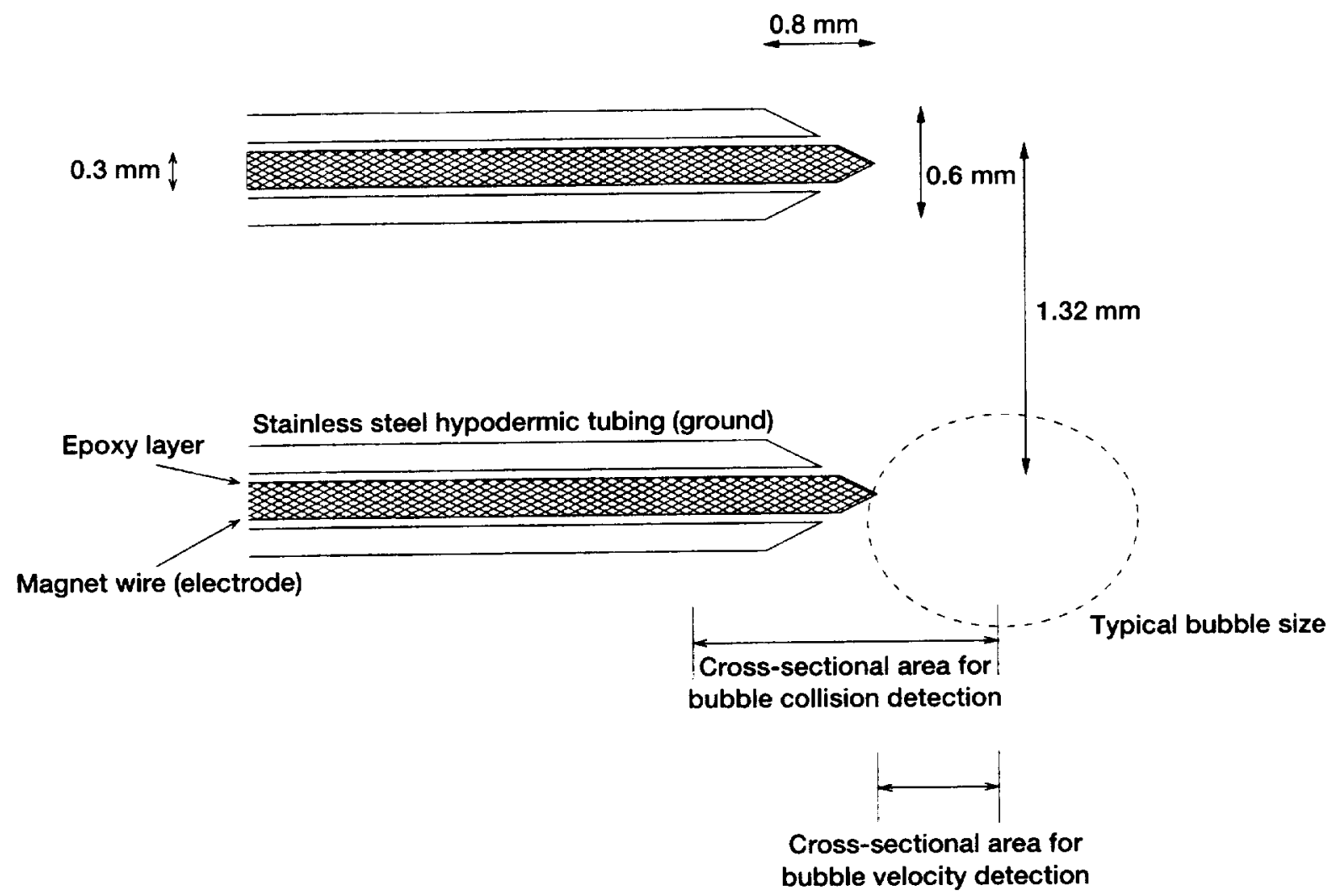

Figure 5.-Schematic of the dual impedance probe. The figure is drawn to scale. 


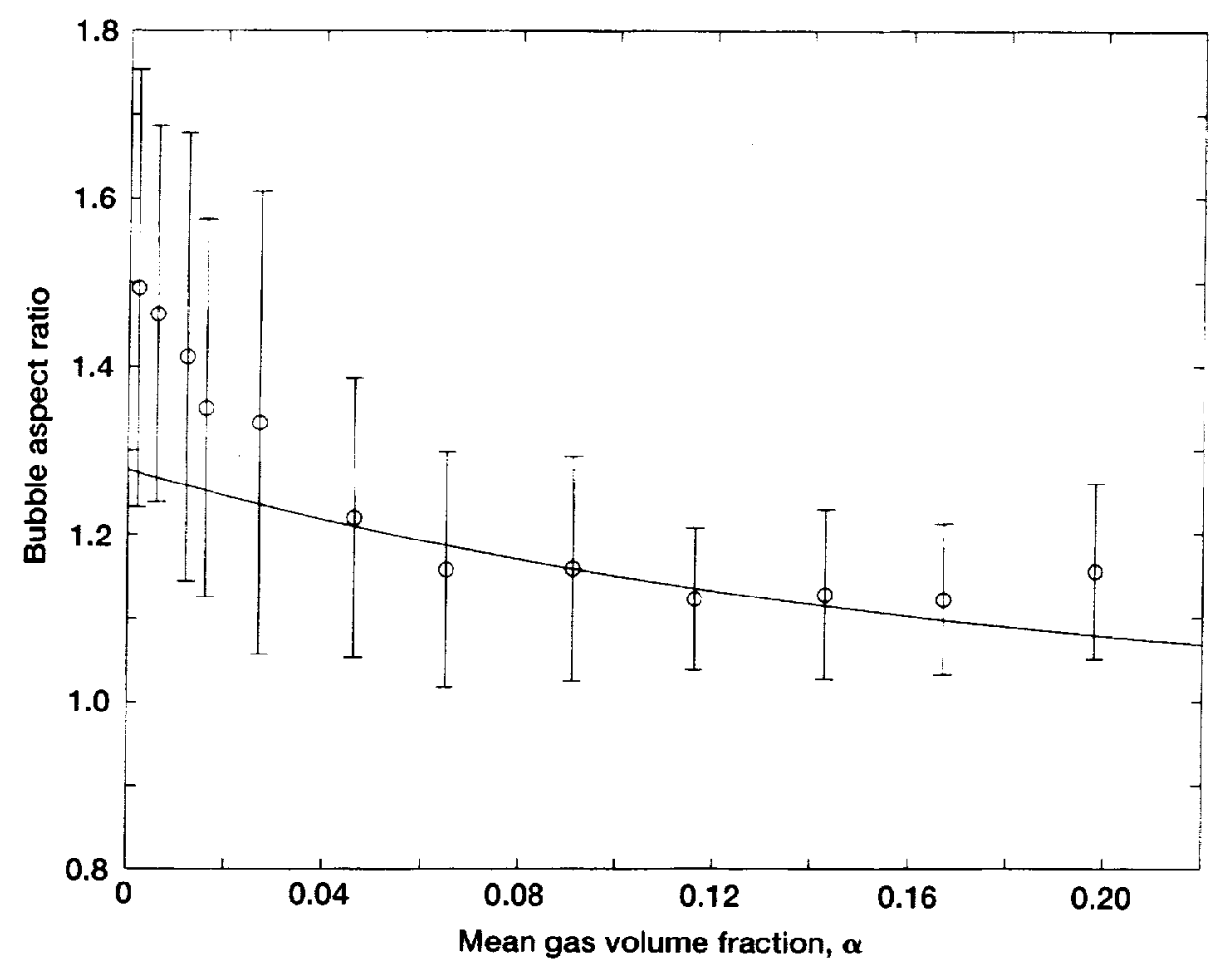

Figure 6.-Bubble aspect ratio, $\chi$, as a function of mean gas volume fraction, $\alpha$. The bars indicate the bubble aspect ratio standard deviation. Measurements obtained $50 \mathrm{~cm}$ above the bubbler. The solid line presents the prediction from Moore's work, 1965.

Bubbles are produced in the Couette through 19 capillary tubes (0.02-in.-diameter) spaced equidistant along the height of the Couette and attached to one of the splice plates on the Couette inner cylinder. The 19 bubblers translate in and out of the Couette $(0$ to $2.5 \mathrm{~cm}$ from the inner wall), driven by $5 \mathrm{VDC}, 4.6 \mathrm{~W}$ motor. The position of the bubblers relative to the stationary inner wall affects the bubble size produced. An identical motor drives a similar mechanism that supports an impedance and a hot wire probe.

The hot wire probe (used to determine the fluid velocity) and dual impedance probes (used to determine bubble location and velocity) are mounted to the splice plate 90 degrees counter-clockwise from the bubblers and travel from 0 to $2.5 \mathrm{~cm}$ across the $3 \mathrm{~cm}$ gap between the inner and outer wall of the Couette. This hot wire probe has a conical tip and is expected to be more rugged than previous wire probes. A new signal conditioning unit has been designed and fabricated for the impedance probe circuits.

The separator assembly consists of an acrylic cylindrical chamber that houses 2 concentric acrylic cones with holes machined into the cone sides. The chamber is coupled to a motor that spins the cones at approximately $2500 \mathrm{rpm}$. When a mixture of gas and liquid enter the separator in the volume between the cones, the liquid is forced to the outside through the holes in the spinning cones into the cylindrical chamber. The gas in the separator forms a distinct core at the center of the inner cone. A gas/liquid detector is mounted in the separator and software control is used for automatic operation. When gas is detected, a solenoid valve opens and the gas is removed by a vacuum pump. When liquid is detected, the solenoid valve closes so that no liquid is removed through the gas vent line. A pump is used to remove the gas/liquid mixture from the Couette test chamber into the separator. The same pump, pushes the bubble free water back into the Couette test chamber in preparation for making a new bubble suspension that the researchers are interested in studying. Figure 10 shows a picture of the separator used to separate the gasliquid mixture in low gravity.

Video cameras (high and normal speeds) are used to study the bubble generation and to assess the bubble size distribution, coalescence, and bubble-probe interactions.

\section{THEORY}

The equations of motion for large Reynolds number, spherical bubble suspensions have been derived from first principles using theory and numerical simulations. ${ }^{13}$ The 


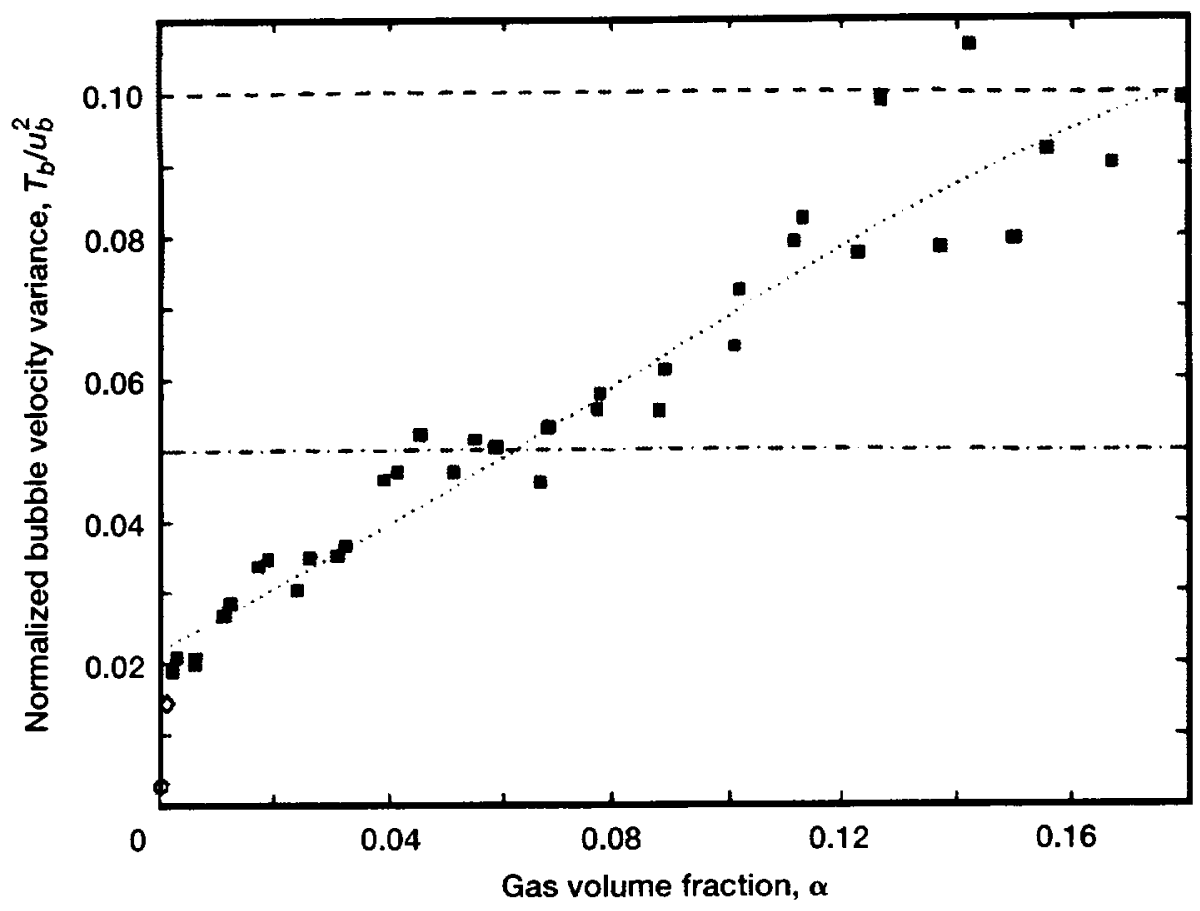

Figure 7.-Normalized bubble vertical velocity variance as a function of mean gas volume fraction. The solid squares show the measurements using the dual impedance probe. The dashed and dash-dot lines represent the values of $A$ used for the bubble velocity predictions for Spelt \& Sangani (1998); the dotted line is the fit to the measurements. The circle shows the bubble velocity variance measured for a single bubble in the channel. The diamond represents the bubble velocity variance measured in a very dilute suspension.

equations consist of two sets: one for the bubble phase and one for the mixture of gas and liquid. The bubble phase equations are

$$
\begin{gathered}
\frac{\partial \phi}{\partial t}+\frac{\partial\left(\phi V_{i}\right)}{\partial x_{i}}=0 \\
\frac{d l_{i}}{d t}=-\frac{1}{n} \frac{\partial P_{i j}}{\partial x_{j}}-m g_{i}-12 \pi \mu a C_{d} V_{i} \\
+m \frac{D U_{i}}{D t}-I_{j} \frac{\partial U_{i}}{\partial x_{j}}
\end{gathered}
$$

where $\phi$ is the bubble volume fraction, $t$ the time, $V$, the average bubble velocity relative to the mixture velocity $U_{i}, l_{i}$ the virtual momentum of the bubbles, $n$ the number density of the bubbles, $P_{i j}$ the bubble phase stress tensor, $m$ the volume of the bubble multiplied by the liquid density, $g_{i}$ the gravitational acceleration, $a$ the radius of the bubbles, $C_{d}$ the drag coefficient. $\mu$ the liquid viscosity, $d / d t$ the time derivative following the motion of bubbles and $D / D t$ the time derivative following the motion of the gas-liquid mixture. The virtual momentum of the bubbles is given by $I_{i}=(\mathrm{m} / 2) \mathrm{CaV}, \mathrm{Ca}$ being the virtual mass coefficient. The bubble-phase stress is given by

$$
\begin{aligned}
P_{i j}=\frac{\rho}{2} \phi T(1+4 \chi \phi) & \delta_{i j}-\frac{\rho}{2} G^{2} \delta_{i j} \\
& -\left(\kappa-\frac{2 \mu_{s}}{3}\right) e_{k k} \delta_{i j}-2 \mu_{s} e_{i j}
\end{aligned}
$$

where $T$ is the bubble phase temperature, defined as onethird of the bubble velocity variance, $\chi$ the radial distribution function value at $2 a, \kappa$ and $\mu_{\mathrm{s}}$ the bubblephase viscosities, $G_{i}=-(\mathrm{Ca} / 2+1) V_{i}$, and $e_{i j}$ the rate of strain tensor for the bubble phase. The isotropic part of the bubble phase stress is the bubble phase pressure. The bubble-phase stress and the other properties such as the bubble-phase viscosities depend on the bubble phase temperature and therefore an additional equation is required for the balance of bubble fluctuation energy. This equation. the continuity and momentum equations for the mixture. and the closure relations for the bubble phase viscosity, 


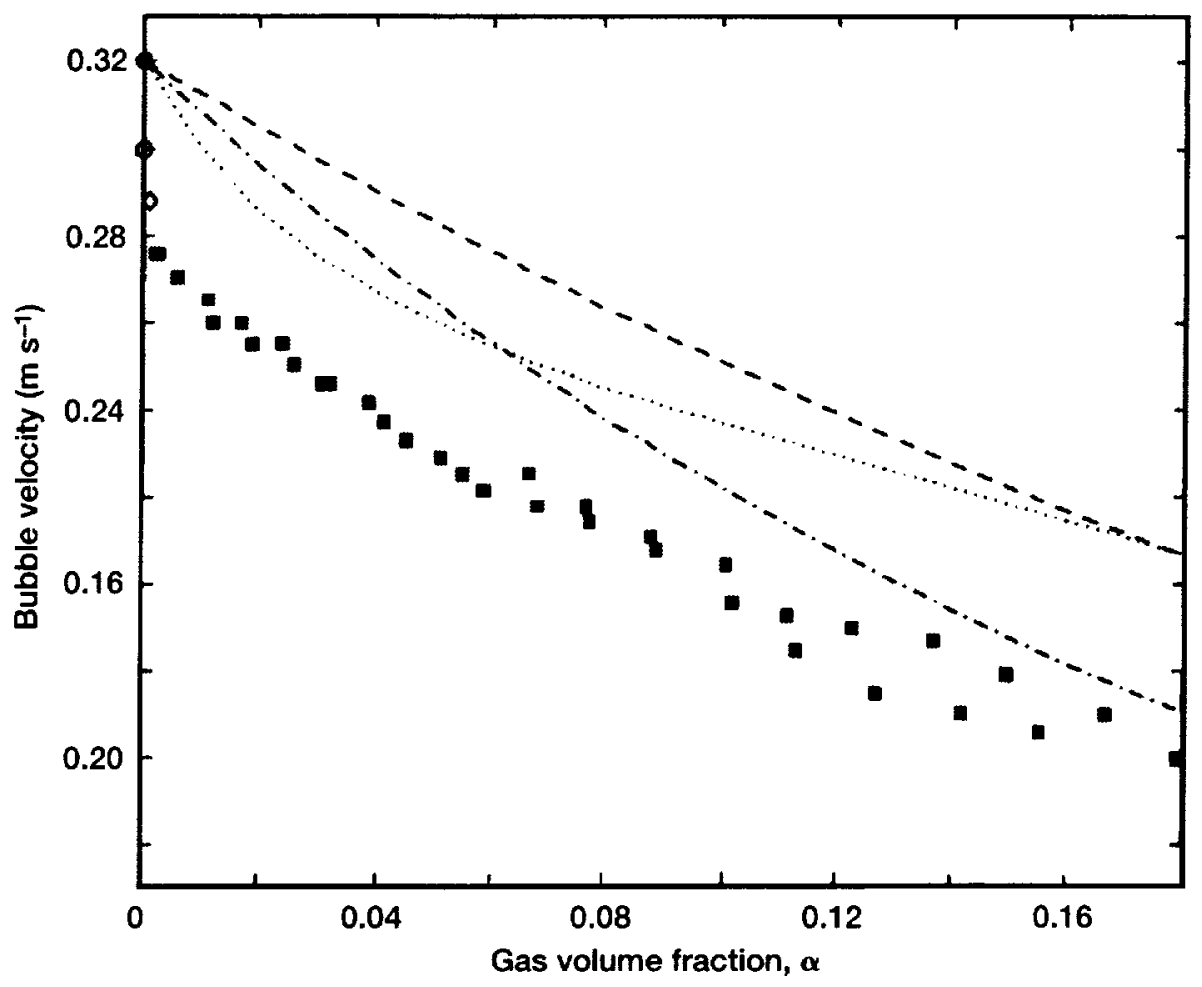

Figure 8.-Bubble velocity as a function of mean gas volume fraction. The solid squares show the measurements using the dual impedance probe. The lines show the predictions from Spelt \& Sangani (1998) using $u_{\infty}=0.320 \mathrm{~m} \mathrm{~s}^{-1}$ and different values of the parameter $A: \cdots, A=10 ;-\cdots, A=20 ; \cdots, A=A(\alpha)$ from experiments. The filled circle shows the terminal velocity of a bubble moving in a large channel $\left(u_{x}=0.320 \mathrm{~m} \mathrm{~s}^{-1}\right)$. The empty circle shows the velocity measured for a single bubble in the experimental channel. The diamond shows the measurement for a very dilute suspension in the channel.

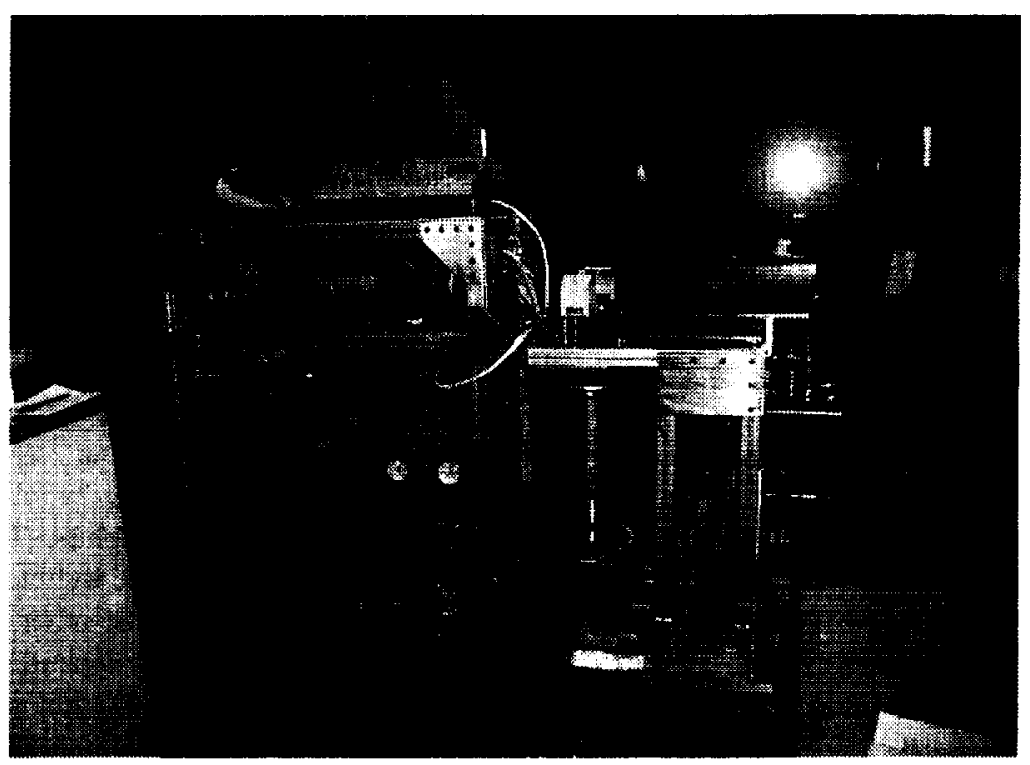

Figure 9.-Picture of the Couette system hardware. 

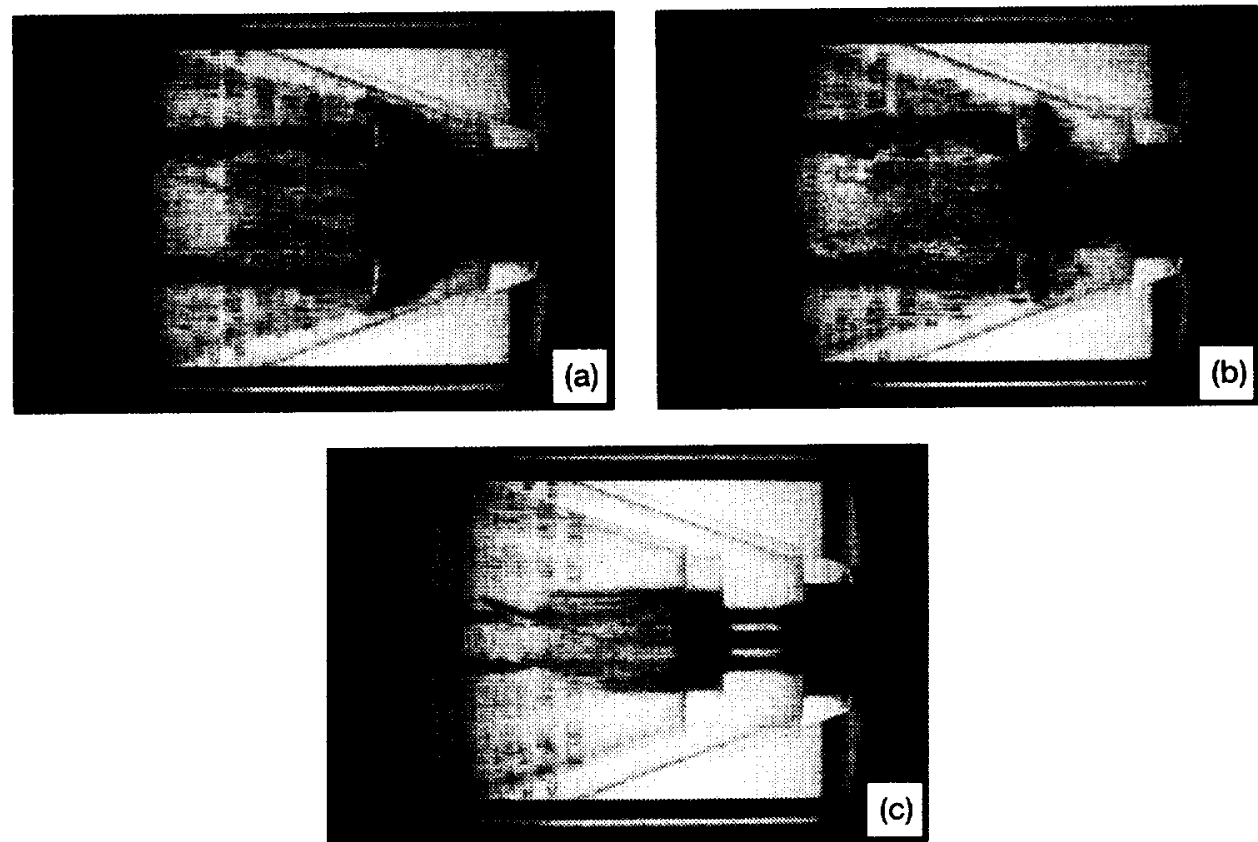

Figure 10.-Photos showing the performance of the separator, (a) in the beginning (b) the middle, and (c) toward the end of the separation process. Note the gas core forming in the middle.

virtual mass coefficient, and viscous drag coefficients may be found in reference 1.3 .

Modifications needed to account for the deviation of the bubbles from the spherical shape were determined in a recent study by Kushch. ${ }^{5}$ This study also examined in detail the problem of collision between two deformable bubbles in the presence of electrolytes which induce shortrange repulsive force between the bubbles and conditions for which the short-range repulsive potential will not be sufficient to arrest the motion of bubbles towards each other leading to coalescence.

The above equations must be supplemented with suitable boundary conditions at wall. The wall-bubble interactions are being currently investigated both analytically and experimentally and numerical simulations will be carried out for different kinds of boundary conditions to determine their influence on the bubble volume fraction and velocity profiles. These will be compared with the experiments carried out in vertical and inclined channels.

\section{REFERENCES}

1. Bagnold, R.A., 1954 Experiments on gravity-free dispersion of large solid spheres in a Newtonian fluid under shear. Proc. R. Soc. Lond. A 225, 49.
2. Biesheuvel, A. and Gorissen. W.C.M.. 1990 Void fraction disturbances in a uniform bubbly fluid. $\mathrm{Int} . J$. Multiphase Flow' 16, 211.

3. Duineveld. P.C., 1995 The rise and shape of bubbles in pure water at high Reynolds number. J. Fluid Mech. 292, 325.

4. Kang, S.-Y., Sangani, A.S., Tsao, H.-K.. and Koch, D.L., 1997 Rheology of dense bubble suspensions. Phys. Fluids 9. 1540.

5. Kushch. V.I.. Sangani, A.S., Spelt.P.D.M.. and Koch. D.L., 2001 Finite Weber number motion of bubbles through a nearly inviscid liquid. J. Fluid Mech. (submitted).

6. Moore, D.W., 1963 The boundary layer on a spherical gas bubble. J. Fluid Mech 16, 161.

7. Moore, D.W., 1965 The velocity of rise of distorted gas bubbles in a liquid of small viscosity. J. Fluid Mech. 23, 749.

8. Nott. P.R. and Brady, J.F., 1994 Pressure-driven flow of suspensions: simulations and theory. J. FluidMech. $275,157$.

9. Oguz. H.N. and Prosperetti. A., 1993 Dynamics of bubble growth and detachment from a needle. $J$. Fluid Mech. 257, 111.

10. Sangani, A.S. and Didwania, A.K., 1993a Disperse phase stress tensor in flows of bubbly liquids at large Reynolds numbers. J. Fluid Mech. 248, 27. 
11. Sangani, A.S. and Didwania, A.K., 1993b Dynamic simulations of flows of bubbly liquids at large Reynolds numbers. J. Fluid Mech. 250, 307.

12. Smereka, P. 1993 On the motion of bubbles in a periodic box. J. Fluid Mech. 254, 79.

13. Spelt, P.D.M. and Sangani, A.S., 1998 Properties and averaged equations for flows of bubbly liquids. Appl. Sci.Res. 58, 337.

14. Tillmark, N. and Alfredson, P.H., 1992 Experiments on transition in plane Couette flow. J. Fluid Mech. 235,89 .
15. Yurkovetsky, Y. and Brady, J.F., 1996 Statistical mechanics of bubbly liquids. Phys. Fluids 8,881 .

16. Zhang, D.Z. and Prospretti, A., 1994 Averaged equations for inviscid disperse two-phase flow. $J$. Fluid Mech. 267, 185.

17. Zenit, R., Koch, D.L., and Sangani, A.S., 2001 Measurements of the average properties of a suspension of bubbles rising in a vertical channel. $J$. Fluid Mech. 429, 307. 

Public reporting burden for this collection of information is estimated to average 1 hour per response, including the time for reviewing instructions, searching existing data sources gathering and maintaining the data needed, and completing and reviewing the collection of information. Send comments regarding this burden estimate or any other aspect of this collection of information, including suggestions for reducing this burden, to Washington Headquarters Services, Directorate for Information Operations and Reports, 1215 Jefferson Davis Highway, Suite 1204. Artington, VA 22202-4302, and to the Otfice of Management and Budget. Paperwork Reduction Project (0704-0188), Washington. DC 20503.

\begin{tabular}{|l|r|r|}
\hline 1. AGENCY USE ONLY (Leave blank) & $\begin{array}{r}\text { 2. REPORT DATE } \\
\text { February 2002 }\end{array}$ & $\begin{array}{r}\text { 3. REPORT TYPE AND DATES COVERED } \\
\text { Technical Memorandum }\end{array}$ \\
\hline
\end{tabular}

4. TITLE AND SUBTITLE

February 2002

5. FUNDING NUMBERS

Behavior of Rapidly Sheared Bubble Suspensions

6. AUTHOR(S)

WU-101-43-0B-00

A.S. Sangani, V.I. Kushch, M. Hoffmann, H. Nahra, D.L. Koch. and Y. Tsang

7. PERFORMING ORGANIZATION NAME(S) AND ADDRESS(ES)

National Aeronautics and Space Administration

John H. Glenn Research Center at Lewis Field

Cleveland, Ohio 44135-3191

8. PERFORMING ORGANIZATION REPORT NUMBER

E-13049

9. SPONSORING/MONITORING AGENCY NAME(S) AND ADDRESS(ES)

10. SPONSORING/MONITORING AGENCY REPORT NUMBER

National Aeronautics and Space Administration

Washington, DC 20546-0001

NASA TM-2002-211203

AIAA-2001-5018

11. SUPPLEMENTARY NOTES

Prepared for the International Space Station Utilization-2001 sponsored by the American Institute of Aeronautics and Astronautics. Cape Canaveral, Florida, October 15-18, 2001. A.S. Sangani and V.I. Kushch, Syracuse University, Department of Chemical Engineering and Materials Science, Syracuse. New York 13244: M. Hoffmann and H. Nahra. NASA Glenn Research Center: D.L. Koch and Y. Tsang, Comell University, Department of Chemical Engineering. Ithaca, New York 14853. Responsible person, H. Nahra. organization code $6712,216-433-5385$.

12a. DISTRIBUTION/AVAILABILITY STATEMENT 12b. DISTRIBUTION CODE

Unclassified - Unlimited

Subject Category: 34

Distribution: Nonstandard

Available electronically at http://gltrs,grc.nasa.gov/GLTRS

This publication is available from the NASA Center for AeroSpace Information, 301-621-0390.

13. ABSTRACT (Maximum 200 words)

An experiment to be carried out aboard the International Space Station is described. A suspension consisting of millimeter-sized bubbles in water containing some dissolved salt, which prevents bubbles from coalescing, will be sheared in a Couette cylindrical cell. Rotation of the outer cylinder will produce centrifugal force which will tend to accumulate the bubbles near the inner wall. The shearing will enhance collisions among bubbles creating thereby bubble phase pressure that will resist the tendency of the bubbles to accumulate near the inner wall. The bubble volume fraction and velocity profiles will be measured and compared with the theoretical predictions. Ground-based research on measurement of bubble phase properties and flow in vertical channel are described.

\section{SUBJECT TERMS}

Bubble suspension; Couette cell; Dual impedance probe; Wall shear stress;

Bubble phase pressure

\section{SECURITY CLASSIFICATION OF REPORT}

Unclassified

\author{
18. SECURITY CLASSIFICATION \\ OF THIS PAGE \\ Unclassified
}

19. SECURITY CLASSIFICATION OF ABSTRACT Unclassified
15. NUMBER OF PAGES 16

16. PRICE CODE

\section{LIMITATION OF ABSTRACT}



